\title{
Are Longer and Heavier Vehicles (LHVs) Beneficial for Society? A Cost Benefit Analysis to Evaluate their Potential Implementation in Spain
}

\author{
A. ORTEGA, J.M. VASSALLO, A.F. GUZMÁN \\ AND P.J. PÉREZ-MARTÍNEZ
}

\begin{abstract}
In this paper we carry out a thorough review of the current research related to the benefits and costs arising from the implementation of longer and heavier vehicles (LHVs). From this review we concluded that despite the many studies available, little has been said about the sensitivity of the benefits and costs to the ultimate performance of the key variables related to the evolution of the economy, road transport performance, safety, and so on. In order to fill this gap, we have designed a sensitivity approach based on a cost benefit analysis tool to determine which variables demonstrate the greatest influence on the benefits and costs stemming from the implementation of LHVs. In order to test the methodology, we have used it in an analysis of the Spanish trunk network. The results show that the benefits of LHVs for society are significant. Even in the least favorable scenario, the economic benefits are greater than $€ 3500$ million over 15 years, and the environment enhanced as well, for $\mathrm{CO}_{2}$ emissions are reduced by 2 Million tonnes. Overall we noted how the results are not very sensitive to the evolution of key variables in determining the final outcome. However, we found that the variables that have the greatest affect on the final benefit, such as traffic growth and social discount rate, depend basically on the performance of the overall economy. Moreover, the private cost for haulers seems to be more important in determining the final benefit than externality costs.
\end{abstract}

\section{Introduction}

In Spain, the road is the dominant mode of surface transportation for domestic freight. It accounts for 93.5\% of total tonne-kilometers in 2010. From 1998 to 2010, the market share of road transportation for domestic freight increased from $92.4 \%$ to $93.5 \%$. By contrast, rail freight transport declined from $4.8 \%$ to $2.7 \%$, while pipeline transport increased from $2.8 \%$ to $3.8 \%$. In Spain, the inland waterway mode is negligible. In this period, the GDP grew by $28.9 \%$ while total domestic freight grew by $17.99 \%$. 
Given the current unbalance, measures to rationalize and increase efficiency of road transport operations can potentially produce greater social and environmental benefits than marginal changes in the transport modal share (European Environment Agency, 2009; Pérez \& Monzón, 2010). In this respect, longer and heavier vehicles (LHVs) are regarded as a means of increasing efficiency through the reduction in the number of vehicles and the decrease in the cost of freight transportation. LHVs, also called Mega trucks, are longer and heavier than the usual articulated trucks. The articulated trucks are 16.50 meters long and 40 tonnes in weight, while the standard length and weight for LHVs are 25.25 meters and 60 tonnes respectively. However, the introduction of LHVs can also prompt negative effects such as a greater severity of accidents. For this reason, the evaluation of the trade-off between advantages and drawbacks is of the greatest interest.

The objective of this paper is threefold: first, to conduct an extensive literature review on the subject; second, to develop a methodology to identify the sensitivity of key variables stemming from the implementation of LHVs on the final outcome using a cost benefit analysis (CBA); and third, to validate this methodology by applying it to the case study of Spain.

Aside from the Introduction, this paper is divided into four additional sections. In the second section, we conduct a review of the current research aimed at assessing the costs and benefits stemming from the widespread introduction of LHVs. In the third section we define the methodology, and describe the data and hypothesis. In the fourth section, we apply the methodology to different LHV configurations, and conduct a sensitivity analysis to identify the most responsive variables. Finally, in the fifth section, we offer a set of conclusions and lessons for policy-makers.

\section{Review}

The literature assessing the economic impact of LHVs is vast and diverse. According to the International Union of Railways Communications Department (2007), the introduction of LHVs may have several effects: transfer of freight from smaller vehicles to bigger ones; induced freight demand; reduction of transportation costs; load consolidation; increase in the severity of accidents; reduction of fuel consumption; and so on. McKinnon (2008) found that three of the key variables for assessing the impact of LHVs are: the degree of load consolidation; the freight modal shift; and induced freight traffic by road. He also noted that these variables are very difficult to predict with accuracy.

EU regulations concerning truck size establishes as a recommendation that member states should adopt a standard truck size of 44 tonnes operating weight, 18.75 meters long, and 4 meters high. This provision is not mandatory so member states are free to set their own standards for domestic traffic. Some European countries, such as Sweden and Finland, have already adopted maximum sizes greater than the recommended European standard. Apart from these Nordics, there are some countries (Norway, Denmark, The Netherlands, and Belgium) that have already conducted pilot tests with the standard LHV size. Other countries, such as France, Germany, UK, Switzerland, Austria, Portugal, and Spain either have conducted studies on the implementation of LHVs, or have implemented pilot tests with vehicles greater than the currently permitted national size, but smaller than the standard LHV size (Ortega \& Vassallo, 2012). 
Most of the research in Europe comes from countries that either have implemented LHVs or are thinking of doing it. The objective of most of the research conducted in Europe up to now has been focused on quantifying economic cost and benefits, evaluating the impact on external costs, and understanding the impact of LHVs on safety. There is also literature from North America whose main concern has been to analyze the impact on LHVs on road infrastructure, bridges, and tunnels, and to evaluate the market niche filled by LHVs.

Below we offer a description of the main impacts from the implementation of LHVs that we have found in the literature review. We categorize these impacts thus: transportation costs and competitiveness; effects on road infrastructure; social benefits and externalities; and safety.

\section{Transportation Costs and Competitiveness}

Most of the research regarding transportation cost savings and competitiveness has been focused on quantifying cost savings per tonne-kilometer, identifying the market niche of LHVs, and analyzing competition with other modes. Overall the studies to date have reported substantial savings and competitiveness gains.

Clayton, Montufar, and Middleton (2003) analyzed the regulations and use of long semitrailers in the USA. On the basis of interviews with different stakeholders involved in this survey, they found some slight differences among the states, and identified a market niche due to both the decreased density of certain payloads, and the fact that large shippers discovered more profitable logistical opportunities.

Regehr, Montufar, and Clayton (2009) studied the effects that size and weight regulations have had on the articulated truck fleet used in recent decades in the Canadian Prairie regions. The engineering policies that were put in place allowed major increases in the weights and dimensions of large trucks. As a result of this, articulated trucks became heavier and larger, and consequently were able to carry more weight and cubic payload.

Bergqvist and Behrends (2011) assessed the effects of longer vehicles on the preand post-haulage cost to gauge the usefulness of LHVs in reducing the cost in intermodal transportation over shorter-i.e. less than 300 kilometers- distances, where the advantages of the intermodal transport system compared with that of direct road are low. They demonstrated that a typical shipper could attain cost reductions of about $5-10 \%$ in the total costs of the intermodal transport chain, and therefore they defended a more flexible legal framework in order to allow the use of LHVs in transport chains. Regarding the competition between rail and road transportation, Bryan, Weisbrod, and Martland (2007) pointed out that rail is not always the best solution for freight capacity, even if in some conditions it can be competitive and effective.

Knight et al. (2008) assessed the likely effects of allowing LHVs in the UK. They found that between $5 \%$ and $10 \%$ of the tonnes-kilometers carried by articulated vehicles could be transferred to LHVs. They also expected a maximum migration of between $8 \%$ and $18 \%$ of total tonnes-kilometers carried by train to LHVs. The internal operation cost per tonne-kilometer would be reduced between 18\% and $43 \%$.

Vierth and Haraldsson (2012) found that for timber transport in Sweden larger vehicles of 90 tonnes and 30 meters would be of both social and economic benefit, provided that no larger investment were necessary in roads. 


\section{Effects on Infrastructure}

The goal of our present research has been to determine the effect of LHVs on infrastructure in order to evaluate whether additional investment is needed and, if it is needed, to arrive at a proper way to quantify it.

The effect of LHVs on infrastructure is twofold. On one hand, more weight means more damage to bridges and other structures. On the other hand, if this additional weight is distributed among a greater number of axles and the total weight per axle is decreased, then the damage to the pavement may end up being smaller (Rufolo, Bronfman, \& Kuhner, 2000).

The first effect has been analyzed by Ghosn and Moses (2000), who studied the effects of changing truck weight regulation in bridges along the US roads. Their proposal consisted of including weight, axles, and distances between them, in order to consider the effect on bridges and their safety. They found that with the new regulations, many bridges could have safety deficiencies when LHVs are traveling over them. Hewitt, Stephens, Smith, and Menuez (1999) assessed the cost for upgrading the bridges of Montana as \$0.9 million if vehicles of 58.1 tonnes were allowed. Stephens, Scoles, Patterson, and Schillings (1997) studied what would be the effects on Montana's highways if there were to be a change in the limits on vehicle size and weight from 53 tonnes and 29 meters length with 8 axles to 60 tonnes and 25 meters with 8 axles. They found no additional costs in dollars per kilometer driven on bridges of the interstate system. However, they calculated an increased cost of 0.07 dollars per kilometer driven over bridges in the primary system. With respect to the additional cost of pavements, this amounted only to 0.01 dollars per kilometer driven in both the interstate and primary systems.

Fortowsky and Humphreys (2006) discovered important savings to the cost of resurfacing the pavement if higher limits of 45 tonnes (or 40 tonnes to special commodities) were allowed along the whole length of Maine's I-95, principally due to the decrease in the diversion of heavy trucks onto state roads. In this same vein, Roberts and Djakfar (2000) pointed out that the design of the pavement is very important in determining the additional cost for allowing heavier trucks. For the Belgian case, Debauche and Decock (2007) demonstrated that depending on the precise LHV configuration, the effects on the infrastructure could vary considerably.

\section{Social Benefits and Externalities}

The research on social benefits and externalities has been focused on quantifying the welfare gains stemming from the introduction of LHVs, and showing the impact of this measure on the reduction of externalities, especially the reduction in $\mathrm{CO}_{2}$ emissions.

In 1995 Sweden permitted the use of LHVs of 25.25 meters in length and 60 tonnes in weight; the results were extremely positive in terms of social benefits and effect on other externalities. Fuel consumption decreased on average by $14.3 \%$. This led to a concomitant reduction of $\mathrm{CO}_{2}$ emissions. The average reduction in fuel consumption varied between $12.9 \%$ and $15.3 \%$, depending on the route. If LHVs had not been allowed, emissions of nitrogen oxides would have increased by $14 \%$ per year (Backman \& Nordström, 2002). LHVs were also allowed in Finland with very good results. Joint studies with Sweden 
demonstrated energy consumption savings above 20\%. For the Belgian case, Debauche and Decock (2007) found a substantial reduction of fuel consumption per tonne transported.

Vierth et al. (2008) assessed the impact of Sweden's returning to the maximum 18.75 meter/40 tonnes limit previously mandated before LHVs were allowed. They found that the return to the use of smaller vehicles would lead to higher transportation costs and would increase environmental and accident costs.

The UK increased the maximum truck weight from 41 to 44 tonnes in 2001. Three years later, the results of this new regulation showed an increase in the number of trucks-kilometers saved and in economic and environmental benefits, than had been forecasted (Mckinnon, 2005).

Bereni and Jacob (2009) used a CBA to study the implementation of LHVs in the EU. They analyzed four different possible scenarios: (1) do nothing; (2) allow standard LHVs throughout the EU; (3) allow standard LHVs only in some transportation corridors; and (4) allow trucks up to 20.75 meters long and 44 tonnes weight. With the exception of the first scenario, where the result by definition remained unchanged, the other scenarios were extremely positive. Depending on the hypothesis and scenario considered, the results varied between $€ 29228$ million (the upper value in the second scenario) and $€ 1587$ million (lower value in the fourth scenario) in amounts saved.

One of the most recent studies regarding the performance of different kinds of trucks around the world was done by Glaeser and Ritzinger (2012). They selected 10 trucks of a possible 38 for a study commissioned by the OECD called 'Moving freight with better trucks.' For each vehicle the optimum cargo density in $t / \mathrm{m}^{3}$, productivity in relation to both energy consumption and $\mathrm{CO}_{2}$ emissions, the dynamic behavior and active safety, and the vehicle impact on the road surface were calculated and analyzed. They found there would be a clear gain both in productivity and in emissions efficiency if LHVs were allowed.

\section{Safety}

The research conducted on safety has been focused on identifying the impact that the implementation of LHVs may have on accidents on the road networks. In this respect we have not found unanimity of results in the literature.

Hanley and Forkenbrock (2005) studied the safety of passing longer vehicles on two-lane highways. They concluded that there would be an increase in the probability of accidents when cars chose to pass those longer vehicles. Obviously, this problem would not occur if LHVs traveled on highways allowing only one-way traffic. Grislis (2010) evaluated the effect in road safety of longer combination vehicles (LCVs). He was not able to find empirical evidence that these vehicles, particularly shorter LCVs of 25.25 meters, are significantly more dangerous than standard heavy vehicles. He also noted that observed results differ depending on the country and region being studied.

For the Belgian case, Debauche and Decock (2007) did not find any clear evidence of an increase in the level of accident risk. However, for the German case, Glaeser et al. (2006) predicted an increase in the severity of accidents in the case of head-on collisions and, in the case of fire in tunnels, much more severe consequences. In a study for the UK, Knight et al. (2008) noted an increase of safety risk per vehicle, but a decrease of safety risk per tonne of freight carried. Glaeser and Ritzinger (2012) recommended that the introduction of LHVs should be limited to 
those roads meeting certain criteria that made them capable of safely accommodating LHVs.

\section{Research Gaps}

One of the most glaring gaps we have identified in our review of the literature is the lack of a sensitivity analysis that attempts to identify the influence of such key variables as the evolution of the economy, the kind and amount of freight that would eventually migrate to LHVs, the percentage of empty returns, and similar matters, on the ultimate costs and benefits of permitting the use of LHVs. We only found one report (Christidis \& Leduc, 2009) with a sensitivity analysis regarding the introduction of LHVs into use. However, this sensitivity analysis was conducted at a macro level for the whole of Europe, and only for a single-year period.

In this research we intend to define a methodology based on a CBA approach to evaluate the impact of the implementation of LHVs on social welfare from a microeconomic standpoint. On the basis of this methodology, we will employ a sensitivity analysis intended to evaluate the impact of key parameters. We apply this methodology in a case study of Spain.

\section{Methodology, Data, and Hypothesis}

\section{Cost Benefit and Sensitivity Analysis}

The economic framework used for assessing the socioeconomic impact of increasing the maximum size of trucks is the CBA (Campbell \& Brown, 2005). The CBA consists of comparing the costs and benefits resulting from each of two scenarios, described in monetary terms, throughout the expected life of the policy that is being evaluated. The base scenario (the do-nothing scenario) is identical to the current one, while the scenario of analysis (the do-something scenario) attempts to measure the impact if the government were to introduce a new regulation allowing LHVs in some Spanish roads. Future benefits and costs are discounted to their current value through the social discount rate commonly used by governments to evaluate public policies. If the discounted benefits and costs of the scenario of analysis exceed the discounted costs and benefits of the base scenario, then the policy adopted is said to be economically profitable for the society because a social welfare gain is expected. The difference between benefits and costs over the project lifespan is referred to as net present value (NPV). This NPV it is calculated as depicted in (1):

$$
\mathrm{NPV}=\sum_{t=0}^{n}\left(\frac{1}{1+r}\right)^{t} x\left[\mathrm{TC}_{t}^{\mathrm{dn}}-\mathrm{TC}_{t}^{\mathrm{LHVs}}+\mathrm{BID}_{t}^{\mathrm{LHVs}}\right]
$$

where $r$ is the social discount rate, $t$ the period of time for the analysis, $\mathrm{TC}_{t}^{\mathrm{dn}}$ the total cost in year $\mathrm{t}$ for the base scenario (do-nothing), $\mathrm{TC}_{t}^{\mathrm{LHVs}}$ the total cost in year $\mathrm{t}$ for the scenario of analysis (LHVs scenario), and BID $t{ }^{\mathrm{LHV}}$ the benefit derived from the induced demand for the LHVs scenario. 
Every cost is calculated for both alternatives, do nothing $(d n)$ and introduction of LHVs, during the period of time analyzed. Then, the benefit (or loss) due to the induced demand for year $t$ is calculated and added to Equation (1) and the result will show the socioeconomic gain (or loss) derived from the new policy. The consequence of the induced demand will depend on whether the vehicles do or do not internalize the externalities they produce through taxes and tolls. If the vehicles do it, then the effect would be positive for the society. If they do not do it, the effect would be negative.

There are two most important changes derived from the introduction of LHVs. First, increasing the weight and length of the vehicles implies reducing operation costs per tonne-kilometer moved. Second, the reduction in the number of vehicles decreases externalities. These two effects are positive. On the other hand, there might be other negative effects such as an increase in the severity of accidents, or an increase in the number of trucks that return partly or completely empty, if there is not enough freight to fill the larger volume. In Table 1, we show the expected effects, and whether they are considered positive or negative according to the CBA.

De Palma, Picard, and Andrieu (2012) highlight that risks and uncertainty are not easily taken into account in CBA assessments. In order to overcome these shortfalls, different approaches have been used in order to include risks and uncertainties such as: (1) value at risk (VaR); (2) conditional value at risk; (3) downside risk measures, and (4) efficiency ratio. VaR is defined by Tapiero (2005) as the expected loss arising from an adverse market movement with specified probability over a period of time. Further, Gregory and Reeves (2008) distinguish three methodologies for calculate VaR: (1) historical simulation; (2) variance co-variance based on normality; and (3) Monte Carlo simulation from a known distribution. The goal of running a Monte Carlo simulation is to model uncertainty more accurately, choosing randomly modifiable values in each iteration. As we will explain later, some of the key variables for the final result of the CBA may vary within a wide range of values. For this reason we decided to enhance the CBA with a sensitivity analysis whose goal is to identify which variables have a greater impact on the final CBA outcome. In order to do it, we will employ the Monte Carlo simulation.

For the CBA, we decided to set up an evaluation period of 15 years duration, starting from the introduction of LHVs. A shorter period is not sufficient to take

Table 1. Expected effects for CBA assessment.

\begin{tabular}{lcc}
\hline Effect considered & Evolution of the variable & Effect on the CBA \\
\hline Number of vehicles & $\downarrow$ & Positive \\
Induced demand & $\uparrow$ & Undetermined \\
Number of accidents & $\downarrow$ & Positive \\
Severity of accidents & $\uparrow$ & Negative \\
Maintenance cost of the roads & $\uparrow$ & Negative \\
Travel time (congestion) & $=$ & Neutral \\
Transportation costs & $\downarrow$ & Positive \\
Net emissions & $\downarrow$ & Positive \\
Empty returns & $\uparrow$ & Negative \\
Investment in roads & $\uparrow$ & Negative \\
\hline
\end{tabular}


into full account the benefits while a longer period introduces a lot of uncertainty in the variables and hypothesis adopted. The social discount rate adopted was $4.5 \%$, following the work of Evans and Sezer (2005). However, we decided to conduct a sensitivity analysis in a range between $3 \%$ and $6 \%$. For the traffic growth, we adopted a 1.5\% constant growth in line with the growths experienced by other European countries when they reached a similar development as Spain. However, just as we did with the discount rate, we decided to test in the sensitivity analysis a range between $0 \%$ and $3 \%$.

\section{Selection of Corridors, Investment and Vehicle Configuration}

The criteria we adopted to choose the interurban corridors where LHVs will be allowed to drive are the following:

- LHVs will be able to be driven on highways but not on conventional roads. The reason is that the alignment of highways in Spain would enable LHVs to drive with slight additional works, whereas conventional roads would require substantial works.

- The highways chosen must have an annual average daily heavy traffic higher than 1500 vehicles to justify the additional works necessary to enable LHVs to be driven on those highways.

- The highways selected must connect the most important logistical areas in the country, such as harbors and transportation hubs.

On the basis of these criteria, we ended up selecting a LHV network 6600 kilometers long. This road network does not have any connectivity problem between highways and transportation hubs, since the roundabouts and curves that link them have the minimum turning radio recommended of 20 meters to avoid turning problems for LHVs (Oficemen, 2009). According to the Spanish legislation for road bridges, every bridge with a table top wider than 12 meters constructed or renovated since 1998 must be able to bear simultaneously two carriages of loads of 60 tonnes each. This means at least two LHVs fully loaded. As the highways selected for the LHV network already possess these characteristics, we assumed that no large investments will be necessary to adapt bridges and roundabouts. However, following some of the results of the studies conducted abroad, we still decided to assume that some changes will initially be required to adapt the infrastructure for the use of LHVs. Following the figures provided by these studies we introduced in our analysis an initial investment amount falling in a range between $€ 150$ to 1000 million.

Three different LHV configurations were studied in the CBA (Table 2). These configurations have been taken from Debauche and Decock (2007).

\section{Evolution of Type of Vehicles and Freight Demand}

Regarding the evolution of the truck fleet in Spain over the years, we have noted that the number of articulated vehicles has been increasing over the years along with the size of the vehicles. Figure 1(a) shows the distribution of loaded and unloaded vehicle-kilometers in 1997 sorted by type of articulated and rigid vehicles and by maximum payload weight per vehicle. Figure 1(b) represents this distribution in 2008. It is important to note that ever since 1997 there has 
Table 2. LHVs configurations.

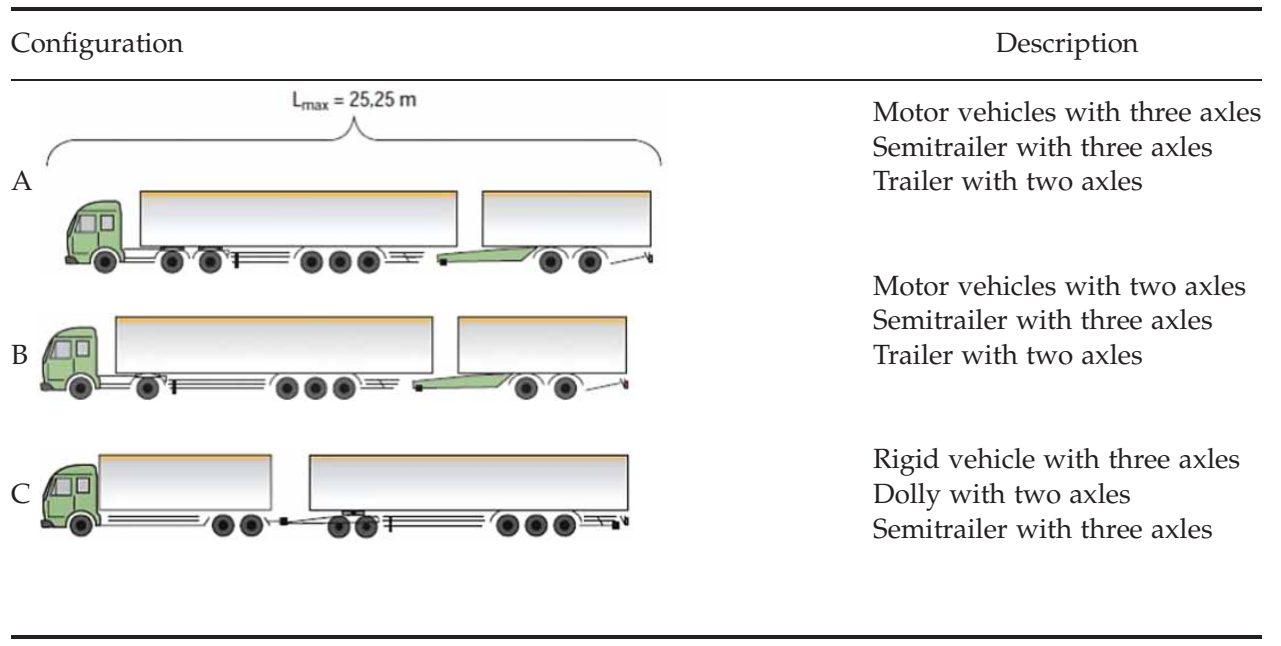

Source: Debauche and Decock (2007).

not been any substantial change in the national legislation concerning the maximum tonnage, number of axles and height for trucks in Spain. The change introduced in 1997 was to allow trucks with 6 axles up to 44 tonnes weight, and to increase their maximum size to 18.75 meters length and 2.55 meters wide, while the maximum height remained 4 meters. Nowadays the most common truck in Spanish interurban roads has 5 axles, a maximum weight of 40 tonnes, and a maximum length of 16.5 meters. It corresponds to the motor vehicle and semitrailer of configuration B.

We assumed that vehicles lighter than 26 tonnes will be mostly used for shortdistance trips so they will never be replaced by LHVs. In our analysis we will consider that only three types of vehicles would be replaced to LHVs: rigid vehicles of 26 tonnes weight or more, articulated vehicles between 32 and 38 tonnes, and articulated vehicles between 38 and 44 tonnes. Presently, these vehicles are the biggest ones on the Spanish roads. They travel distances longer than 200 kilometers corresponding to interurban movements. For this reason, a transfer rate from these three kinds of trucks to the LHVs has been adopted. This vehicle transfer rate means the demand diverted from each kind of vehicle to LHVs (from the do-nothing scenario to the LHV scenario). The maximum and minimum scenarios have been chosen according to the evolution observed in Figure 1. This range is greater than has been forecasted by Knight et al. (2008).

As well as considering a transfer rate, we have studied the effects of induced demand, which is the additional freight demand due to transportation cost reduction caused by the introduction of LHVs. There is little evidence that the increase and use of the maximum weight limits can generate significant additional transport demand (Commission for Integrated Transport, 2000).We posit a range of induced demand between $5 \%$ and $10 \%$ of the total freight that migrated to LHVs.

We have estimated that LHVs would be introduced progressively during a period of 6 years corresponding to the amortization period of truck trailers. The acquisition of trucks by haulers would occur gradually according to the pace at which the trucking companies renew their fleets. 
(a)

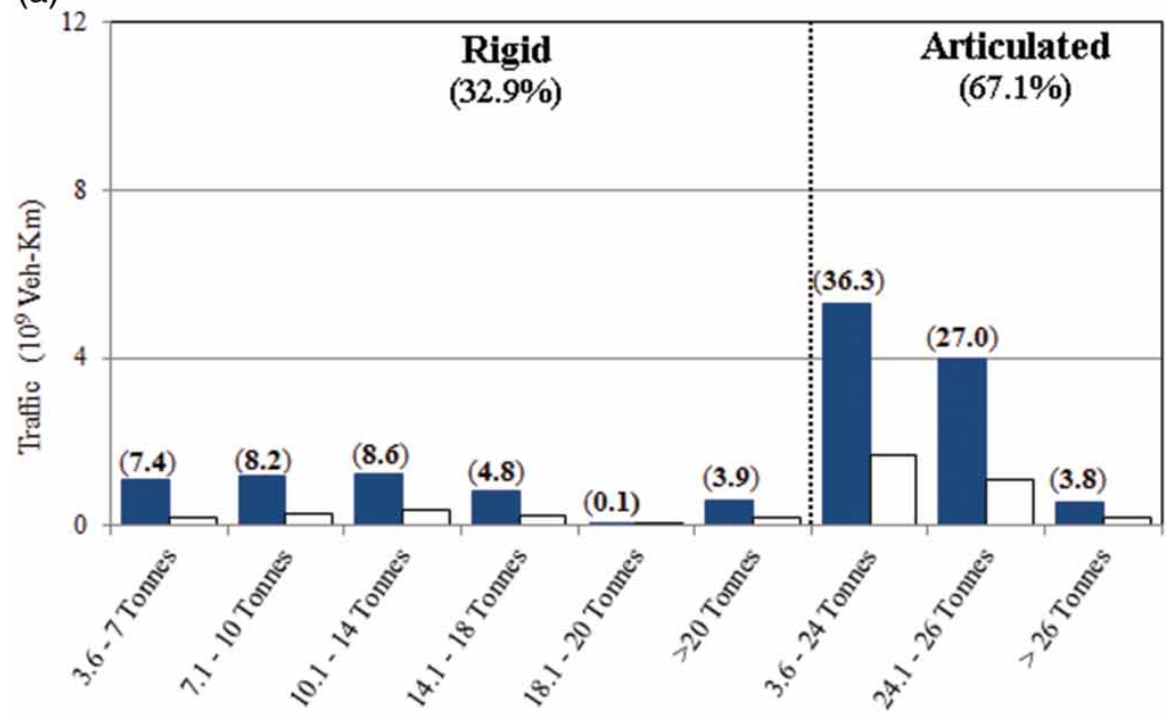

(b)

Vehicle Type and Maximum Payload (Tonnes)

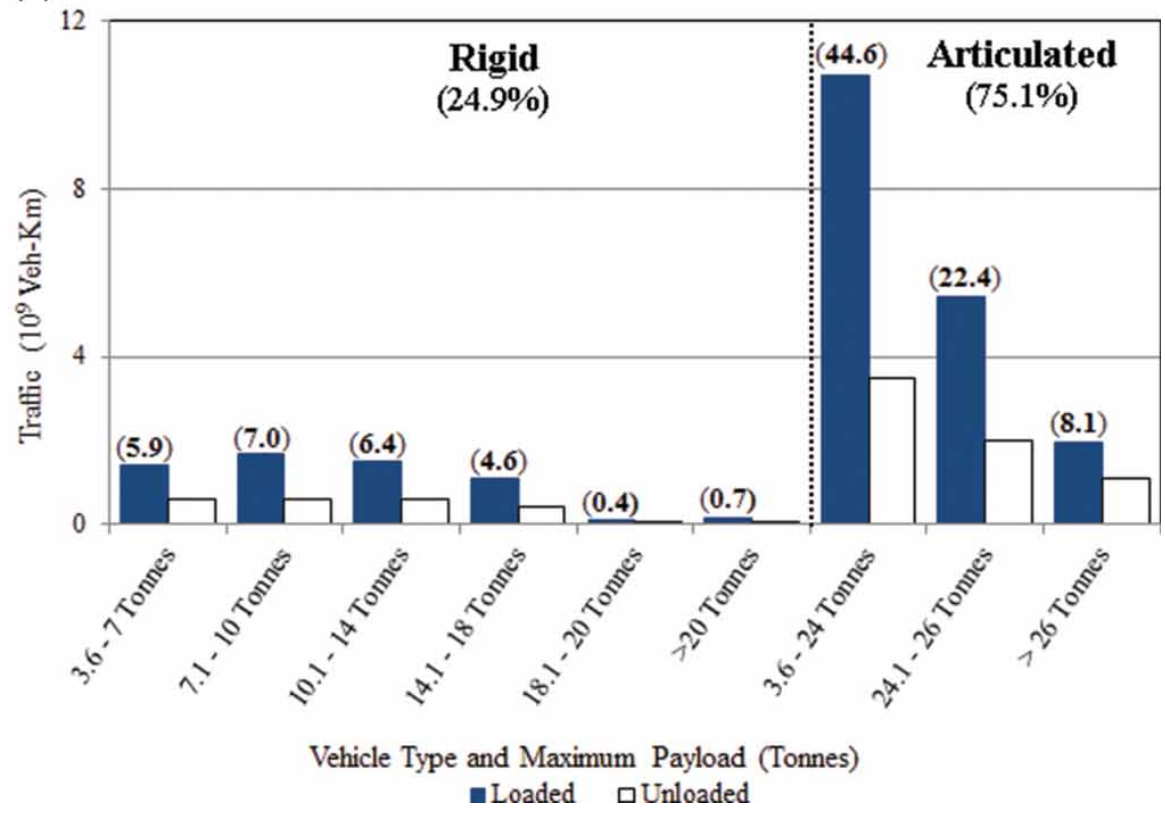

Figure 1. Distribution of loaded and unloaded vehicle-kilometers for Spain. (a) 1997 and (b) 2008.

We have also assumed that certain types of commodities such as petrol and chemical products will never migrate to LHVs for both safety and logistic reasons. These commodities are $8.8 \%$ of the total tonne-kilometers moved by road in Spain in the year 2008. Finally, the transfer of freight from rail to road has not been considered in this methodology, mainly because the market share of domestic freight rail transportation in Spain is so low that any transfer would be negligible. 


\section{Operation, Infrastructure and Externality Costs}

The three types of costs considered in the CBA are operation costs, externality costs, and maintenance infrastructure costs. The operation costs of these vehicles were taken from data provided by a survey conducted by the government of Spain in 2008. To calculate the operation costs of LHVs we took data from private haulers who have operated those trucks, as well as from pilot studies conducted in Spain and abroad $(\mathrm{K}+\mathrm{P}, 2011)$. As a final result, the cost per tonne transported by the LHVs is $22 \%$ fewer than in the articulated truck of 40 tonnes.

To calculate accurately the operation cost, it is necessary to obtain the ratio of maximum payload and volume constraints, and the percentage of empty returns, for LHVs. The ratio of maximum payload and volume constraint should reflect the number of trucks necessary to transport the freight of an LHV. This ratio varies depending on whether the capacity of the truck is restricted either in volume or weight. For instance, an LHV is able to carry between 2.29 and 2.50 times the freight of a rigid vehicle.

Haulers usually operate with trucks fully loaded, but in Spain 15\% of the trips are accounted to be empty returns. As LHVs are larger, they are supposed to be more difficult to fill so we expect a slightly greater percentage of empty returns. For this reason we assumed that these returns may vary in a range between $15 \%$ and $18 \%$.

To calculate the costs of wear and tear caused by LHVs on the infrastructure, we considered the number of axles and the distances between the axles and the specific size of trailers and semitrailers - 7.82 meters for trailer, and 13.60 meters for semitrailer (UIC, 2007) - for each type of configuration. On the basis of that, we proceeded to calculate the infrastructure cost for pavements, structures, geometry of the tracks, tunnels, safety barriers, and parking. Further information about that calculation can be seen in Ortega, Vassallo, and Pérez (2011).

As for the externalities, we have relied on the average costs calculated by Vassallo, López, and Pérez-Martínez (2012) for Spain. We have calculated the external costs for LHVs by having that calculation reflect the greater fuel consumption for LHVs, 35\% more per vehicle, compared to a conventional articulated vehicle of 40 tonnes (Ortega \& Vassallo, 2012). We introduced a greater cost per accident for LHVs compared to the 40-tonnes for articulated trucks because of the effect of bigger size. However, the literature is not conclusive as to whether they increase or decrease with the introduction of LHVs. On the one hand, allowing LHVs means fewer heavy vehicles in the road network so this should imply fewer accidents and consequently fewer costs. On the other hand, the severity of the accidents that do occur is assumed to be greater because LHVs are larger. In order to be conservative in our analysis, we decided to calculate on the assumption of greater accident costs where LHVs are involved - between $5 \%$ and $9 \%$ greater than a conventional 40 tonnes truck.

Regarding the evolution of costs over time, we introduced two trends in our analysis: first, a gradual increase in the efficiency of the vehicle engines leading to a gradual reduction of fuel consumption to $10 \%$ by the end of the analysis; second, a gradual reduction in the emissions due to the reduction of fuel consumption and to the technological improvements of the vehicle engines. Also, we adopted a variation in the fuel price in a range between $-30 \%$ and $+60 \%$ from the present price. In this sense, the two most important costs for haulers are fuel and labor costs. While prices in Spain between 2000 and 2010 increased 
by almost $33 \%$, transportation costs for 40 -tonne vehicles increased by $33.5 \%$ (from $0.745 € /$ kilometer in year 2000 to $0.995 € /$ kilometer in year 2010). In the same period, fuel costs increased by $46.85 \%$ and labor costs increased by $35.79 \%$. These figures demonstrate the efficiency gains of the industry in that decade, attained mostly through reduction of fuel consumption.

Finally, we did not consider the effect of congestion because interurban roads in Spain have little congestion. Traffic jam is triggered by cars during special events and seasonal fluctuations, such as the beginning or end of summer vacations, or long weekends, when bigger trucks have been forbidden from being on the roads. (Aparicio, 2012).

\section{Summary of Variables and Ranges}

Table 3 summarizes the ranges of the variables influencing the transport policy measure whose impact is calculated in this paper. The analysis was performed through a Monte Carlo simulation, considering a random number generator executed using Excel VBA, and assuming a normal distribution with a standard deviation ensuring the variability between the minimum and the maximum values. Two thousand Monte Carlo simulation runs were conducted considering the mean, minimum, and maximum value of each parameter as well as the standard deviation.

\section{Results}

The results of the CBA for each LHV configuration are sorted and plotted as histograms and cumulative probability distribution curves (also called value at risk and gain curve (VARG)) in order to display the range of possible outcomes (Figure 2).

Table 3. Selected CBA parameter values.

\begin{tabular}{|c|c|c|c|}
\hline & Parameter analyzed & Min. value & Max. value \\
\hline \multirow{4}{*}{$\begin{array}{l}\text { Demand } \\
\text { changes }\end{array}$} & Rigid vehicle transferred to LHVs & $75 \%$ & $95 \%$ \\
\hline & 32-38 tonne articulated vehicle transferred to LHVs & $60 \%$ & $80 \%$ \\
\hline & $38-44$ tonne articulated vehicle transferred to LHVs & $40 \%$ & $60 \%$ \\
\hline & Induced demand & $5 \%$ & $10 \%$ \\
\hline \multirow[t]{8}{*}{ Costs } & $\begin{array}{l}\text { Rigid vehicles ratio of maximum payload and volume } \\
\text { constraints }\end{array}$ & 2.29 & 2.50 \\
\hline & $\begin{array}{l}\text { 32-38 tonne articulated vehicle ratio of maximum } \\
\text { payload and volume constraints }\end{array}$ & 1.81 & 1.90 \\
\hline & $\begin{array}{l}\text { 38-44 tonne articulated vehicle ratio of maximum } \\
\text { payload and volume constraints }\end{array}$ & 1.5 & 1.6 \\
\hline & LHVs empty returns & $15 \%$ & $18 \%$ \\
\hline & Accidents & $5 \%$ & $9 \%$ \\
\hline & Fuel price & $-30 \%$ & $60 \%$ \\
\hline & Investment & $€ 150$ & $€ 1000$ \\
\hline & & million & million \\
\hline \multirow[t]{2}{*}{ Economic } & Discount rate ${ }^{\mathrm{a}}$ & $3 \%$ & $6 \%$ \\
\hline & Traffic growth rate ${ }^{a}$ & $0 \%$ & $3 \%$ \\
\hline
\end{tabular}

\footnotetext{
a Analyzed through tornado graph only.
} 


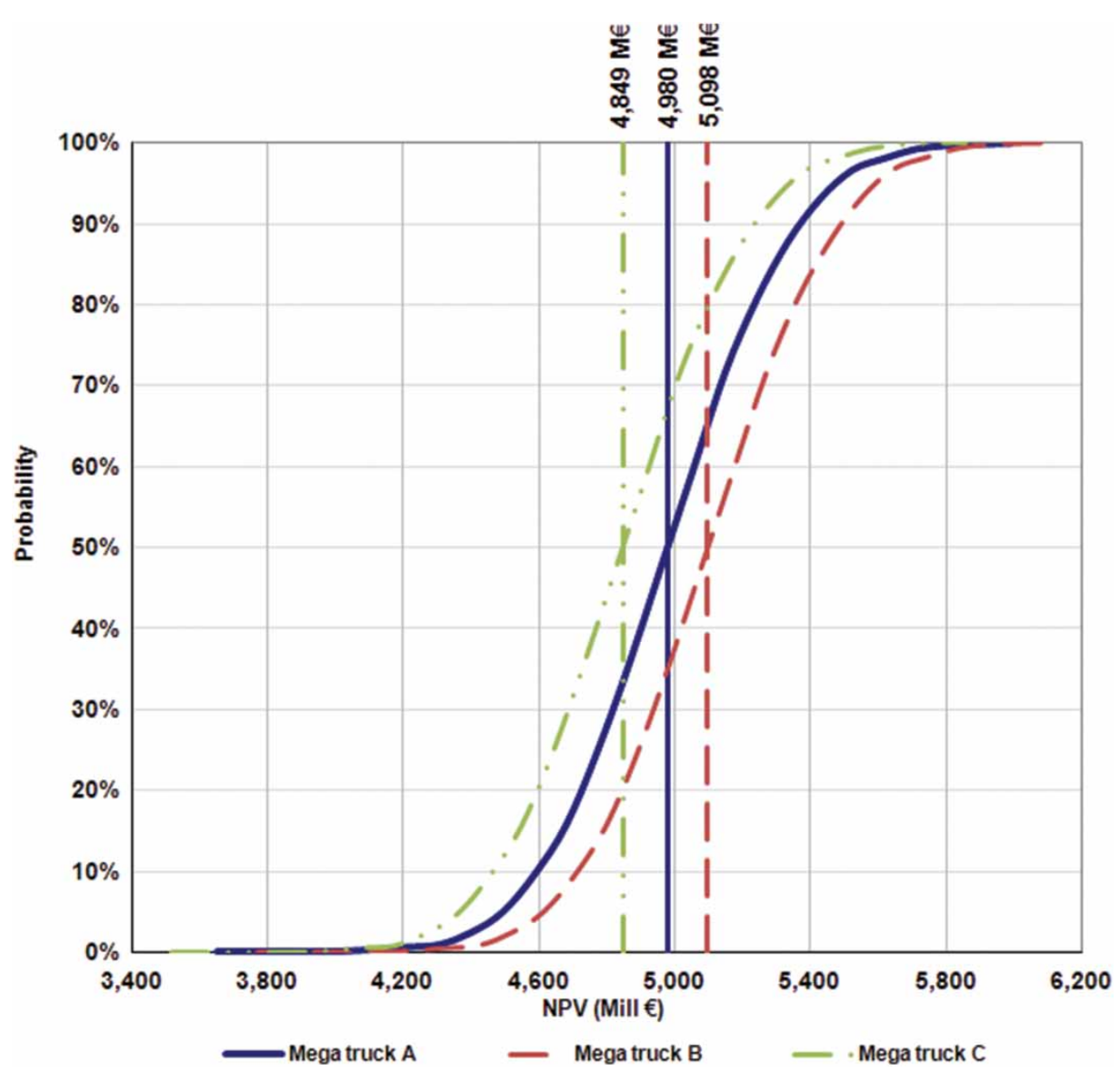

Figure 2. CBA VARG distributions for the three LHVs configurations.

Figure 2 shows how the cumulative probability distribution curves have the shape of a cumulative normal, since we selected each variable to fluctuate between minimum and maximum values according to a normal distribution. In the most likely option, the social benefits of allowing LHVs in the selected network would be $€ 4980$ million for configuration A, $€ 5098$ million for configuration $B$, and $€ 4849$ million for configuration $C$. The results show how Configuration $B$ is always the best option irrespective of the sensitivity analysis adopted in the methodology. The final outcome in terms of social welfare is always positive and fairly stable over the sensitivity analysis. The worst-case scenario for configuration $C$ still produces a global benefit greater than $€ 3500$ million. These results demonstrate that the outcome of the analysis is quite robust.

Table 4 summarizes the results of the CBA for the three LHV configurations. It shows the maximum NPV, minimum NPV, and expected NPV (mean). The table also displays the VARG that shows the probability of each LHV configuration for NPV values. It reveals the likelihood of getting a NPV smaller than a given value (VAR) or greater than a certain value (value at gain-VAG). Table 4 shows that the most advantageous LHV configuration turns out to be configuration B. This option improves the expected NPV, reduces the downside risk, and improves the upside gain. Table 4 depicts as well the VAR as the $10 \%$ chance of having 
Table 4. NPV from the CBA parameter values.

\begin{tabular}{lccr}
\hline & \multicolumn{3}{c}{ CBA NPV (€ million) LHV configuration } \\
\cline { 2 - 4 } CBA NPN & A & B & C \\
\hline Min. & 3651 & 3769 & 3519 \\
Max. & 5991 & 6112 & 5857 \\
Expected (Mean) & 4980 & 5098 & 4849 \\
VAR 10\% & 4593 & 4711 & 4463 \\
VAG 90\% & 5372 & 5493 & 5239 \\
\hline
\end{tabular}

NPV lower than $€ 4593$; $€ 4711$; and $€ 4463$ million for each configuration, that is A, $\mathrm{B}$, and $\mathrm{C}$ respectively. It also shows the VAG with a $10 \%$ probability of having an NPV higher than $€ 5372 ; € 5493$; and $€ 5239$ million for each configuration. In other words, with a probability of $80 \%$ the NPV will be between these two values for each configuration. The mean of the distribution is equivalent to the expected NPV from the CBA.

A final test was conducted to analyze the sensitivity of the results to the variation range of certain variables for configuration $\mathrm{B}$, which according to these results is the most favorable one. The analysis was conducted through a tornado diagram to show the sensitivity of the NPV to the variables used in the methodology while keeping the remaining variables constant (Figure 3). On the left side of this figure, we find all the variables determining the final outcome in terms of net present social value. Next to the definition of each variable, in brackets, we display the variation range tested for each variable. The bars of Figure 3 show the deviation of the NPV from the average value for Configuration B (€5098 million), when this variable changes in the range previously defined and the rest of the variables adopt their average values.

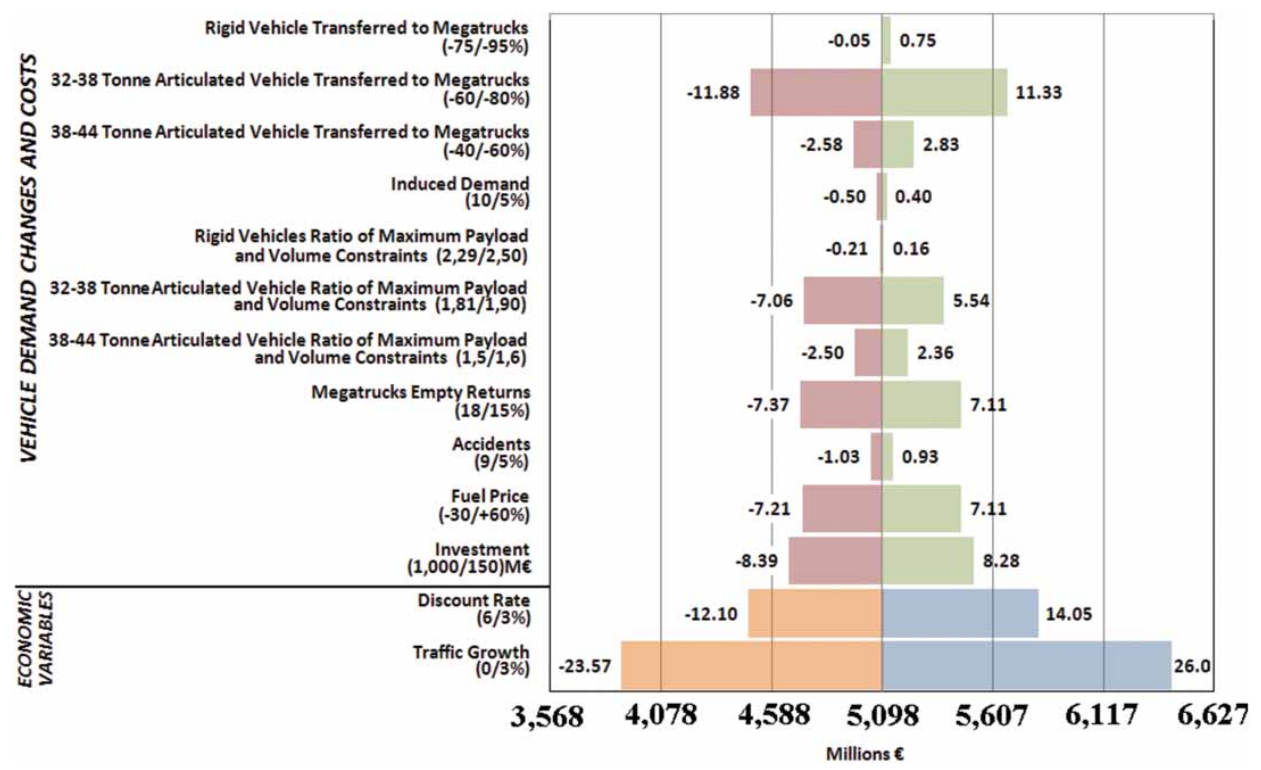

Figure 3. CBA Sensitivity analysis for LHVs configuration B. 
We have distinguished the economic variables (discount rate and traffic growth) from the rest of the variables by depicting them at the bottom of the figure and in different colors. For these two economic variables, the orange color means a loss below the average whereas the blue one represents a gain over the average. By contrast, for the parameters associated with changes in vehicle demand and in costs the red color indicates losses below the average whereas the green color means gains over the average. At the end of each bar a figure is set showing the maximum and minimum effect corresponding to the extremes of the range studied for each variable to the NPV.

For instance, if the increase in induced demand has a maximum value of $10 \%$, the NPV will decrease by $0.50 \%$ in comparison with the average value, but if the increase in induced demand attains the value of 5\%, the NPV will increase by $0.40 \%$. Each $1 \%$ of induced demand will decrease the NPV by $0.18 \%$. This means that the additional demand would not be profitable for the society because it does not internalize the externalities it produces even though this effect is very low.

From the previous figure, we can claim that the two variables that affect the final outcome the most are traffic growth and the social discount rate. Unfortunately, these variables cannot be managed by planners in the decision-making process of putting LHVs into circulation. Figure 3 shows how NPV will be $23.57 \%$ less than the average if, in the end, traffic growth is $0 \%$, and $26.00 \%$ more than the average if, in the end, the annual traffic grows by $3 \%$. As for the discount rate, in the worst-case scenario, with a discount rate of $6 \%$ the social benefit would be reduced by $12.10 \%$, but if the discount rate is 3\%, the NPV will increase by over $14 \%$. If the discount rate decreases only $1 \%$, the NPV will increase by $8.72 \%$.

There are four other variables that also have a notable effect on the final outcome of the CBA: the transfer rate from articulated vehicles of 32-38 tonnes to LHVs; the ratio of maximum payload and volume constraints for this type of vehicle; the empty returns; and finally, the initial investment necessary to enable LHVs to safely use the network.

The first two seem reasonable since the articulated vehicles of 32-38 tonnes account for almost $25 \%$ of the total vehicle-kilometers in the Spanish road network. The variable that indicates the percentage of empty trucks is also important because moving empty vehicles will directly imply an economic loss of time, fuel, amortization, etc. Initial investment is also an important variable because its cost is concentrated in the first years and, as we have seen in the Review section, its effect can become a policy not socially profitable. The influence of fuel price is important to consider because fuel prices have become rather volatile. However, the analysis shows that the impact of such movement in fuel prices is not as important as might be assumed. A $1 \%$ increase in fuel price will imply just a variation of $-0.16 \%$ in the final result in terms of NPV.

Other variables such as the percentage of migration of freight-hauling from articulated vehicles of 38-44 tonnes, and from rigid vehicles as well, appear to have a minor effect on the final outcome in terms of NPV. This shows that the larger the current fleet of vehicles of a certain type, the larger the influence on the NPV of the migration from these types of vehicles to LHVs. The ratio of maximum payload and volume constraints for these types of vehicles has a negligible influence on the final outcome. Surprisingly, safety does not appear to be a very sensitive variable. Every $1 \%$ rise in the accident cost will mean a welfare loss of only $-0.49 \%$. 
Table 5. Emissions assessment.

\begin{tabular}{lccc}
\hline & \multicolumn{3}{c}{ Emissions } \\
\cline { 2 - 4 } CASE & $\begin{array}{c}\mathrm{CO}_{2} \text { (million } \\
\text { tonnes) }\end{array}$ & $\begin{array}{c}\mathrm{NO}_{\mathrm{x}} \text { (thousand } \\
\text { tonnes) }\end{array}$ & $\begin{array}{c}\mathrm{PM}_{10} \text { (thousand } \\
\text { tonnes) }\end{array}$ \\
\hline $\begin{array}{l}\text { Do nothing (expected } \\
\text { year 7*) }\end{array}$ & 3.2 & 76.9 & 2.7 \\
LHV B (expected year $7^{*}$ ) & 3 & 71.5 & 2.5 \\
Expected scenario accumulated 15 years & 51.8 & 1216 & 42.6 \\
Do nothing & 48.2 & 1134 & 39.8 \\
LHV B (Mean) & 47.4 & 1115 & 39.2 \\
LHV B (Min.) & 49 & 1152 & 40.5 \\
LHV B (Max.) & $3.5(6.84 \%)$ & $82.3(6.76 \%)$ & $2.7(6.41 \%)$ \\
Reduction ${ }^{*}(\%)$ & & & \\
\hline
\end{tabular}

${ }^{\mathrm{a} C}$ Computed with the mean value.

If we compare the results obtained from this research to those to be found in the review of the existing literature, we realize that the main contribution of this paper is the design of a methodology based on a CBA with sensitivity aimed at determining the importance of key variables in the decision-making process of deciding to enter LHVs into use. This methodology may help policy-makers to decide, according to the performance of the freight transport market and the microeconomic characteristics of the truck fleet, whether allowing LHVs in their road networks would be a good or a bad idea for their country or region. Moreover, we have validated the methodology through its application to the case study of Spain, where road freight transport is crucial for the economy.

Finally, the analysis has also accounted for important benefits resulting from the reduction of emissions. For example, in the medium scenario (LHV B), the total reduction during the period subject to our analysis would be very high: $\mathrm{CO}_{2}$ emissions would be 3.542 million tonnes lower, $\mathrm{NO}_{x}$ emissions would be 82293 tonnes lower, and $\mathrm{PM}_{10}$ emissions would be 2734 tonnes lower (Table 5). Obviously, one of the most important benefits from this policy will be the reduction of fuel consumption per tonne-kilometer. This method of analysis for decision-making as to the wisdom of LHVs can contribute to the achievement of the objectives of the White Paper 'Roadmap to a Single European Transport Area-Towards a competitive and resource efficient transport system.'

\section{Conclusions and Policy Lessons}

This research provides a set of interesting conclusions and policy lessons. The CBA demonstrates that the implementation of LHVs in Spain would bring about large benefits for society. Those benefits can mostly be explained as resulting from the decrease of transportation costs per tonne-kilometer. Moreover, we found that those benefits do not change much across different vehicle configurations even though configuration B seems to be the most favorable. The reason for this lies in the fact that this configuration has the lowest operation cost. Moreover, the reduction in the total number of vehicles $-6.5 \%$ of the total vehicle-kilometers — in the corridors selected will be significant even allowing for induced demand. 
We found that the welfare increase, measured through the CBA approach designed in this paper, is not very sensitive to the variation of the key variables explaining the results. The most sensitive variables are those related to the economy - the social discount rate and traffic growth — rather than variables related either to freight transfer or to transportation costs. Traffic growth explains more than $23 \%$ of the final result. The social discount rate is also crucial, since it explains more than $12 \%$ of the final NPV.

The sensitivity of the cost of accidents is negligible because it affects only $1 \%$ of the final result. Induced demand affects less than $0.5 \%$. The results show that the bigger the induced demand, the smaller the total benefit. This means that the benefits of induced demand caused by a reduction of transportation costs are lower than the externalities produced by the induced traffic. The distribution of vehicles, the empty returns, and the ratio of maximum payload and volume constraints have greater influence on the final NPV. This is particularly true for the case involving a higher number of vehicles (articulated 32-38 tonnes). If we study the fuel cost, the variation is approximately $7 \%$ of the final result. Surprisingly, those costs that are spread over society, i.e. externality costs, are not very important in the final result. Private costs are hence crucial for the success of this measure. The greater the ability of haulers to operate at the maximum capacity, the greater will be the benefits.

Aparicio, A. (2012, June). Movilidad 2030: Perspectivas a largo plazo de la movilidad interurbana de viajeros en España. Paper presented at the X Congreso de Ingeniería del transporte, Granada.

Backman, H., \& Nordström, R. (2002). Improved performance of European long haulage transport (Report 2002: 6E). Sweden: Transport Research Institute TFK. Retrieved from http:/ /www.modularsystem. eu/download/facts_and_figures/final_report_extra.pdf

Bereni, M., \& Jacob, E. (2009, January). A look into the likely consequences of adapting weights and dimensions of heavy commercial vehicles in Europe. Paper presented at Transportation Research Board 88th Annual Meeting, Washington.

Bergqvist, R., \& Behrends, S. (2011). Assessing the effects of longer vehicles: The case of pre- and posthaulage in intermodal transport chains. Transport Reviews: A Transnational Transdisciplinary Journal, 31(5), 591-602. doi:10.1080/01441647.2011.584980

Bryan, J. G., Weisbrod, G., \& Martland, C. D. (2007). Rail freight as a means of reducing roadway congestion: Feasibility considerations for transportation planning. Transportation Research Record: Journal of the Transportation Research Board, 2008, 75-83. doi:10.3141/2008-10

Campbell, H. F., \& Brown, R. P. (2005). A multiple account framework for cost-benefit analysis. Evaluation and Program Planning, 28(1), 23-32. Retrieved from http://dx.doi.org/10.1016/j.evalprogplan. 2004.05.001

Christidis, P., \& Leduc, G. (2009). Longer and heavier vehicles for freight transport (Report). Sevilla: European Commission Joint Research Centre Institute for Prospective Technological Studies.

Clayton, A., Montufar, J., \& Middleton, D. (2003). Operation of long semitrailers in the United States. Transportation Research Record: Journal of the Transportation Research Board, 1833, 79-86. doi:10.3141/ 1833-11

Commission for Integrated Transport. (2000). Interim report: Permitting 44 tonne lorries for general use in the UK. London: Commission for Integrated Transport. Retrieved from http://webarchive. nationalarchives.gov.uk/20110304132839/http://cfit.independent.gov.uk/pubs/2000/44tonne/ 44tonne/pdf/44tonne.pdf

Debauche, W., \& Decock, D. (2007, September). Longer and heavier goods vehicles (LHVS): A multidisciplinary approach to the issue in Belgium. Paper presented at Choice for Sustainable Development. Pre-Proceedings of the 23rd PIARRC World Road Congress, Paris.

De Palma, A., Picard, N., \& Andrieu, L. (2012). Risk in transport investments. Networks and Spatial Economics, 12(2), 187-204. doi:10.1007/s11067-009-9109-8 
European Environment Agency. (2009). Transport at a crossroads. TERM 2008: Indicators tracking transport and environment in the European Union (Report no. 3/2009). Copenhagen: European Environment Agency, EEA. Retrieved from http://www.eea.europa.eu/publications/transport-at-a-crossroads

Evans, D. J., \& Sezer, H. (2005). Social discount rates for member countries of the European Union. Journal of Economic Studies, 32, 47-59. doi:10.1108/01443580510574832

Fortowsky, J. K., \& Humphreys, J. (2006). Estimating traffic changes and pavement impacts from freight truck diversion following changes in interstate truck weight limits. Transportation Research Record: Journal of the Transportation Research Board, 1966, 71-79. doi:10.3141/1966-09

Ghosn, M., \& Moses, F. (2000). Effect of changing truck weight regulations on U.S. bridge network: Part II. Journal of Bridge Engineering, 5(4), 304-310. Retrieved from http://dx.doi.org/10.1061/ (ASCE)1084-0702(2000)5:4(304)

Glaeser, K., Kaschner, M., Lerner, G., Roder, C., Weber, R., Wolf, A., \& Zander, U. (2006). Effects of new vehicle concepts on the infrastructure of the federal truck road network (Final Report). Federal Republic of Germany: Federal Highway Research Institute, Bast.

Glaeser, K., \& Ritzinger, A. (2012). Comparison of the performance of heavy vehicles results of the OECD study: "Moving freight with better trucks". Procedia-Social and Behavioral Sciences, 48, 106-120. Retrieved from http:/ / dx.doi.org/10.1016/j.sbspro.2012.06.992

Gregory, A. W., \& Reeves, J. J. (2008). Interpreting value at risk (VaR) forecasts. Economic Systems, 32(2), 167-176. Retrieved from http://dx.doi.org/10.1016/j.ecosys.2007.03.001

Grislis, A. (2010). Longer combination vehicles and road safety. Transport, 25(3), 336-343. doi:10.3846/ transport.2010.41

Hanley, P. F., \& Forkenbrock, D. J. (2005). Safety of passing longer combination vehicles on two-lane highways. Transportation Research Part A: Policy and Practice, 39, 1-15. doi:10.1016/j.tra.2004.09.001

Hewitt, J., Stephens, J., Smith, K., \& Menuez, N. (1999). Infrastructure and economic impacts of changes in truck weight regulations in Montana. Transportation Research Record: Journal of the Transportation Research Board, 1653, 42-51. doi:10.3141/1653-06

International Union of Railways Communications Department. (2007). Mega-trucks versus rail freight? What the admission of mega-trucks would really mean for Europe Facts and arguments. Paris: UIC. Retrieved from http:/ / www.uic.org/etf/publication/publication-detail.php?code_pub=511_02

Knight, I., Newton, W., McKinnon, A., Palmer, A., Barlow, T., McCrae, I., ... Taylor, N. (2008). Longer and/or longer and heavier goods vehicles (LHVs)—a study of the likely effects if permitted in the UK: Final Report (Final Report). UK: TRL study for the UK DfT. Retrieved from http://www.trl.co.uk/ online_store/reports_publications/trl_reports/cat_vehicle_engineering/report_Longer_and/or_ Longer_and_Heavier_Goods_Vehicles_LHVs__a_Study_of_the_Effects_if_Permitted_in_the_UK_ Final_Report.htm

$\mathrm{K}+\mathrm{P}$. (2011). Study on the effects of the introduction of LHVs on combined road-rail transport and single wagonload rail freight traffic (Report of October 2011 in cooperation with Fraunhofer ISI). Retrieved from http: / / www.cer.be/publications/studies/studies-details/study-on-the-effects-of-the-introduction-of-lhvs-oncombined-road-rail-transport-and-single-wagonload-rail-freight-traffic/

McKinnon, A. C. (2005). The economic and environmental benefits of increasing maximum truck weight: The British experience. Transportation Research Part D: Transport and Environment, 10(1), 7795. doi:10.1016/j.trd.2004.09.006

McKinnon, A. C. (2008). Should the maximum length and weight of trucks be increased? A review of european evidence. Presented at International Symposium on Logistics, Bangkok.

Oficemen. (2009, September). Estudio sobre la viabilidad de la mejora del transporte de mercancías mediante el uso de vehículos de gran capacidad (Mega-trucks) y la necesidad de adecuación de infraestructuras. Presented at Colegio de Ingenieros de Caminos, Canales y Puertos, Madrid.

Ortega, A., \& Vassallo, J. M. (2012, June). El Megatruck en España: ¿Camino hacia una mejora energética y medioambiental?. Paper presented at the X Congreso de Ingeniería del transporte, Granada.

Ortega, A., Vassallo, J. M., \& Perez, P. J. (2011). Efecto de la implantación del vehículo de 25,25 y 60 Ton. en España. Balance del incremento de las dimensiones y capacidad de carga máximas de los vehículos pesados de transporte por carretera. Madrid: Fundación Corell. Retrieved from http: / www.fundacion-fcorell.es / index.php?option $=$ com_booklibrary\&task $=$ view\&id $=40 \&$ catid $=0 \&$ Itemid $=63$

Pérez, P. J., \& Monzón, A. (2010, July). La eficiencia energética y ambiental de los modos de transporte en España. Paper presented at XVI Congreso Panamericano de Ingeniería de Tránsito y Transporte y Logística, Lisbon. Retrieved from http:/ / oa.upm.es/7420/

Regehr, J. D., Montufar, J., \& Clayton, A. (2009). Lessons learned about the impacts of size and weight regulations on the articulated truck fleet in the Canadian prairie region. Canadian Journal of Civil Engineering, 36(4), 607-616. doi:10.1139/L09-011 
Roberts, F. L., \& Djakfar, L. (2000). Cost of pavement damage due to heavier loads on Louisiana highways: Preliminary assessment. Transportation Research Record: Journal of the Transportation Research Board, 1732, 3-11. doi:10.3141/1732-01

Rufolo, A. M., Bronfman, L., \& Kuhner, E. (2000). Effect of Oregon's axle-weight-distance tax incentive. Transportation Research Record: Journal of the Transportation Research Board, 1732, 63-69. doi:10.3141/ 1732-08

Stephens, J., Scoles, J., Patterson, S., \& Schillings, P. (1997). Impact on Montana's highways of adopting CANADIAN interprovincial and canamex limits on vehicle size and weight. Transportation Research Record: Journal of the Transportation Research Board, 1602, 31-38. doi:10.3141/1602-05

Tapiero, C. S. (2005). Production, manufacturing and logistics value at risk and inventory control. European Journal of Operational Research, 163(3), 769-775. Retrieved from http:/ /dx.doi.org/10.1016/j.ejor. 2003.05.005

Vassallo, J. M., López, E., \& Pérez-Martínez, P. J. (2012). Do charges to freight trucks and trains in the European Union reflect their social marginal cost? Application to the case of Spain. Road E Transport Research, 21, 13-24. Retrieved from http://search.informit.com.au/documentSummary;dn=2085484565 26784;res=IELENG

Vierth, I., Berell, H., McDaniel, J., Haraldsson, M., Hammarström, U., Mohammad-Reza, Y., ... Björketun, U. (2008). The effects of long and heavy trucks on the transport system. Stockholm: VTI. Retrieved from http://www.vti.se/en/publications/the-effects-of-long-and-heavy-trucks-on-the-transportsystem-report-on-a-government-assignment/

Vierth, I., \& Haraldsson. M. (2012, September). Socio-economic effects of longer and/or heavier road transport vehicles-the Swedish case. Presented at International Symposium on Heavy Vehicle Transport Technology, Stockholm. 